\title{
Factors Influencing Pricing Decisions
}

\section{Abbott J Haron*}

Higher Colleges of Technology, Sharjah, United Arab Emirates

\begin{abstract}
In this paper, we look at factors that affect how marketers set price. The final price for a product might be influenced by numerous factors, which can be categorized into two main groups, internal factors and external factors, both areas are discussed in further detail in this paper. In addition to discussing the factors that influence international marketing channels, which are the channels within which goods and services pass to reach their foreign customers. This suggests that manufacturers and consumers must be located in either the producers or customers country or having presence in both countries. Lastly, the paper will discuss standardized advertising versus localized advertising in an international market.
\end{abstract}

Keywords: Marketing; Pricing decisions; Channel structures; Channel strategies; Standardized advertising; Localized advertising

\section{Factors that Affect Price in any Market and Pricing Decision}

This paper has divided the factors, which affect pricing and piecing decisions into two main categories, both categories are explain in detail below:

\section{Internal factors}

When setting price, marketers need to take into consideration several factors, which are the result of company choices and actions. Largely, these factors are controlled by the company and, if needed, can be altered by them [1]. However, while the business may have control over these factors, making a quick change is not always realistic [2]. For example, product pricing may depend on the productivity of a manufacturing facility. The marketer knows that increasing output can reduce the cost of manufacturing each product and thus allow the marketer to potentially reduce the product's price. However, increasing output may require major changes at the manufacturing facility that will take time and will not translate into lower price products for a substantial period [3].

Marketing decisions are directed by the overall objectives of the company. It is important to appreciate that all marketing decisions, including price, work to help achieve company objectives [4].

- $\quad$ Return on Investment (ROI)-A firm may set as a marketing objective, the prerequisite that all products achieve a certain percentage return on the organization's spending on marketing the product. This level of return along with an estimate of sales will help determine suitable pricing levels needed to meet the ROI objective [5].

- Cash flow-Firms might seek to set prices at a level that will insure that sales income will cover product production and marketing costs. This is most likely to happen with new products where the organizational objectives permit a new product to simply meet its expenditures while efforts are made to establish the product in the market [6].

- $\quad$ Market share-The pricing decision might be important when the firm has a goal of gaining a hold in a new market or retaining a certain percentage of an existing market [7].

- $\quad$ Maximize profits-Mature products that appeal to a market that is no longer growing may have a company target requiring the price be set at a level that optimizes profits.

- Fixed costs-Likewise referred to as overhead costs, these represent costs the marketing organization sustains that are not affected by level of production or sales.

- Variable costs-These costs are directly related with the production and sales of products and, consequently, might change as the level of manufacture or sales changes. Typically variable costs are assessed on a per-unit basis since the cost is directly connected to individual items $[8,9]$.

\section{External factors}

There are a number of swaying factors, which are not controlled by the company but will influence pricing decisions. Understanding these factors necessitates the marketer conduct research to monitor what is happening in each market the company serves since the consequence of these factors can vary by market.

- $\quad$ Elasticity of demand-Understanding how price changes influence the market necessitates the marketer have a firm understanding of the idea economists call elasticity of demand, which relates to how purchase amount changes as prices change [10].

- Customer expectations-Possibly the most noticeable external factors that influence price setting, are the expectations of customers and channel partners. When it comes to making a purchase decision customers assess the overall "worth" of a product much more than they assess the price [11]. When deciding on a price marketers need to conduct consumer research to determine what "price points" is satisfactory [12].

- Direct competitor pricing-Almost all marketing decisions, including pricing, will contain an evaluation of competitors' offerings. The impact of this information on the actual setting of price will be contingent on the competitive nature of the market. For example, products that dominate markets and are viewed as market leaders might not be heavily influenced by competitor pricing since they are in a commanding position to set prices as they see fit [13].

- $\quad$ Related product pricing-Products that offer new ways

*Corresponding author: Abbott J Haron, Higher Colleges of Technology, Sharjah, United Arab Emirates, Tel: 06-5054-418; E-mail: abbottjharon@gmail.com

Received December 13, 2015; Accepted Janaury 29, 2016; Published January 30,2016

Citation: Haron AJ (2016) Factors Influencing Pricing Decisions. Int J Econ Manag Sci 5: 312. doi:10.4172/2162-6359.1000312

Copyright: ( 2016 Haron AJ. This is an open-access article distributed under the terms of the Creative Commons Attribution License, which permits unrestricted use, distribution, and reproduction in any medium, provided the original author and source are credited. 
for explaining customer needs may look to pricing of products that consumers are currently using even though these other products might not appear to be direct competitors. For instance, a marketer of a new online golf training service that allows customers to access golf training via their smart phone might look at prices charged by local golf professionals for in-person instruction to measure where to set their price. Although on the surface, online golf training may not be a direct competitor to a golf coach, marketers for the online service can use the cost of in-person instruction as a reference point for setting price.

- $\quad$ Primary product pricing-Marketers may sell products regarded as complementary to a primary product. For example, Bluetooth headsets are considered complementary to the primary product mobile phones. The pricing of complementary products may be affected by pricing variations made to the primary product since customers may compare the price for complementary products based on the primary product price.

- Government regulation-Marketers need to be aware of regulations that influence how price is set in the markets in which their products are sold. These regulations are primarily government endorsed, meaning that there may be legal consequences if the rules are not followed. Price regulations can come from any level of government and vary extensively in their requirements.

\section{Factors that Influence the Channel Structures}

The choice of channel to use is a central decision for the manufacturer where a number of factors and objectives have to be considered as basis for such decision. The international marketer needs clear understanding of market characteristics and must have recognized operating policies before beginning the selection of channel intermediaries [14]. There are a number of factors both objective and subjective and changing from business to business, which governs choice or selection of channel of distribution. Nevertheless, there are some, which stand out and influence channel of distribution choice. They are as follows:

\section{Factors Relating to Product Characteristics}

Product manufactured by a corporation itself is a governing factor in the selection of the channel of distribution. Product characteristics are as follows:

- Industrial or consumer products-When the product being manufactured and sold is industrial in nature, direct channel of distribution is useful because of the relatively small number of clients, need for personal attention, sales clerk's technical qualifications and after-sale servicing etc. However, in case of a consumer product indirect channel of distribution, such as wholesalers, retailers, is most suitable [15].

- Perishability-Perishable goods, such as, vegetables, milk, butter, bakery goods, fruits, seafood etc. need direct selling, as they must reach the consumers as effortlessly as possible after production because of the dangers associated with delays in frequent handling [16].

- Unit value-When the unit value of a product is high, it is typically more economical to choose direct channel of distribution such as company's own sales force than intermediaries are [17]. On the contrary, if the unit value is low and the amount involved in each transaction is generally smaller, it is desired to choose an indirect channel of distribution, i.e. through intermediaries.

- Style obsolescence-When there is high degree of style obsolescence in products like fashion wears, it is desirable to sell direct to retailers who specialize in fashion merchandises.

- Weight and technicality-When the products are bulky, large, and technically complex, it is useful to choose direct channel of distribution.

- $\quad$ Standardized products-When the products are standardized, each unit is similar in shape, size, weight, color, etc. it is useful to choose indirect channel of distribution. On the contrary, if the product is not standardized and is manufactured on order, it is desired to have a direct channel of distribution.

- Purchase frequency-Products that are frequently purchased need direct channel of distribution to decrease the cost and burden of distribution of such products.

\section{Factors Relating to Company Characteristics}

The choice of channel of distribution is also influenced by company's own characteristics as to its size, financial situation, reputation, previous channel experience; present marketing policies, product mix etc. In this connection, some of the main factors are as follows:

- $\quad$ Financial strength-A company, which is financially sound, may engage itself in direct setting. On the contrary, a company, which is financially weak, has to depend on intermediaries and, consequently, has to select indirect channel of distribution, such as Wholesalers, retailers, with robust financial background.

- Marketing policies-The Policies relevant to channel decision might relate to delivery, advertising, after sale service and pricing, etc.

- Size of the company-A large-sized company handling a wide range of products would favor having a direct channel for selling its products. On the contrary, a small-sized company would prefer indirect selling by assigning wholesalers, retailers etc.

- Past channel experience-The past channel experience of the company also effects the choice of selection of the distribution channel. For example, an old and established company with its past good experience of working with certain kinds of intermediaries will like to choose the same channel. However, different will be the case in reverse situation.

- $\quad$ Product mix- The wider is the company's product mix, the superior will be its strength to deal with its customers directly. Likewise, consistency in the company's product mix ensures greater similarity or uniformity in its marketing channels.

- Reputation-It is said that reputation travel faster than the man does. It is true in the case of companies also who wish to select a channel of distribution.

\section{Factors Relating to Market Characteristics}

Market or consumer characteristics refer to buying behaviors, location of market, size of orders, etc. They impact the channel choice meaningfully. They are:

- Consumer purchasing habits-If the consumer anticipates credit facilities, desires personal services of the salesperson, or desires to make all acquisitions at one place, the channel of distribution might be short or long depending on the capacity of the company for providing these facilities. If the manufacturer can afford those facilities, the channel will be shorter, otherwise lengthier. 
- $\quad$ Location of the market-When the customers are spread over a extensive geographical area, the long channel of distribution is most appropriate. On the contrary, if the customers were concentrated and localized, direct selling would be helpful.

- Number of customers-If the number of customers is fairly large, the channel of distribution may be indirect and long, such as wholesalers, retailers, etc. On the contrary, if the number of consumers is small or narrow, direct selling may be valuable.

- $\quad$ Size of orders-Where customers purchase the product in large amounts, direct selling may be preferred. On the contrary, where customers buying the product in small quantities frequently and repeatedly, such as cigarettes, matches, etc., a long distribution channel may be favored.

\section{Factors Relating to Intermediaries Considerations}

The choice of the channel of distribution is also influenced by the intermediaries' considerations. They might include the following:

- Sales volume potential-In selecting channel of distribution, the company should consider the capability of the intermediaries to ensure a targeted sales capacity. The sales capacity potential of the channel may be estimated through market analyses.

- Availability of intermediaries-The Company should make efforts to select aggressively oriented intermediaries. In case they are not obtainable, it is desirable to wait for some time and then to pick-up. In such cases, the company should manage its own channel so long the right types of intermediaries are not available.

- Intermediaries' attitude-If the company follows the resale price maintenance policy, the choice is restricted. On the contrary, if the company allows the intermediaries to adopt their own price policy, the choice is quite wide. Quite a large number of intermediaries would be interested in selling the firm's products.

- Services provided by intermediaries-If the nature of product necessitates after-sale services, repair services; etc., such as cars, scooters etc., only those intermediaries should be appointed who can provide such services, otherwise the company will implement a direct selling channel.

- Cost of channel-Direct selling usually is costlier and thus distribution arranged through intermediaries is more inexpensive.

\section{Standardized Advertising versus Localized Advertising}

Worldwide advertising has been a topic in international advertising for more than twenty years. Recently, many foreign companies have increasingly considered the use of local advertising campaigns in a trend that is apparently in contrast to the move toward country-specific campaigns in the late 1980s [18]. A number of factors are behind the shift, with cost being the most often cited reason [19]. Another consideration is that centrally fashioned advertisements can guarantee a certain standard of quality in markets where expertise is missing [20]. There is also the shift toward more localized management of regional operations among certain firms. Regional advertising makes most sense for companies that offer a product with the same benefits around the world.

Other businesses, however, have decided to launch global campaigns instead. For instance, Levis, Nike, Adidas, and McDonalds have managed their global advertising campaign successfully. The globalization of advertising campaigns suggests a high level of standardization but it often does not fit optimally with the cultures [21] Some experienced multinational marketers like Gillette realized that it is more important for their brand advertising to provoke the same response from consumers across cultures much more than running the same advertising campaign across marketplaces. It might be possible to use the same brand-advertising concept; nevertheless, the executions must be customized to fit local environments.

Raaij recognized four levels of marketing standardization: mission, proposition, concept, and execution. At each level, identical or different essentials may be employed across cultures. Quelch and Hoff proposed a continuum of decision framework used in advertising where a global method can fall anywhere on a spectrum from tight agreement on an advertising model to loose agreement on advertising specifics. That translates into two basic decision frameworks dominant in advertising planning: strategy and execution. Executions can be activated with three levels of adaptation. Firstly, they can be run the same ubiquitously, which usually demands a non-verbal presentation and emphasis more on graphics and music. Secondly, the implementation can be translated from one language to another, and finally, executional differences can be intended to reflect the culture of the local community. That theme remains constant, but the executions are different from one country to another.

According to Mooij, many advertisers alleged wrongly that advertising concepts based on strong image cues, are able to cross borders more easily than campaigns based on verbal communications. They also observed wrongly that advertising themes could be standardized while only the execution might need adaptation. However, even when an advertisement's buying suggestion can be standardized due to similar potentials of products, cultural differences will make it difficult to standardize an advertisement's creative execution style. Cultural ideals are reflected both in advertising themes and in the execution. The central problem in global advertising is the culture match between the values in the advertising message and the values of the receiver. Therefore, international advertisers must understand the dissimilarities in learning and thinking patterns of each market because they affect the way people will process information and react to advertising.

\section{References}

1. Cavusgil TS (1996) Pricing for global markets. The Columbia Journal of World Business 31: 66-78.

2. De Mooij M (2010) Global Marketing: Tailoring Your Strategy to Fit the Culture Deep Insight pp: 24-25

3. Narayandas D, Quelch J, Swartz G (2000) Prepare your company for global pricing. MIT Sloan Management Review 42: 61-70.

4. Kashani K, Quelch JA (1990) Can Sales Promotion Go Global? Business Horizons 33: 37-43.

5. Aaker DA, Shansby JG (1982) Positioning Your Product. Business Horizons 25: 56-62.

6. Aaker DA, Joachimsthaler E (1999) The Lure of Global Branding. Harvard Business Review 77: 137-144.

7. Akaka MA, Alden DL (2010) Global brand positioning and perceptions. International Journal of Advertising 29: 37-56.

8. De Mooij M (2003) Convergence and divergence in consumer behavior: implications for global advertising. International Journal of Advertising 22:183-202.

9. Ger G (1999) Localizing in the global village: Local firms competing in global markets. California Management Review 41: 64-83.

10. Bloom JZ (2005) Market Segmentation: A Neural Network Application. Annals of Tourism Research 32: 93-111. 
11. Holt DB (1995) How Consumers Consume: A Typology of Consumption. Journal of Consumer Research 22: 1-16.

12. Douglas SP (1986) Global Marketing Myopia. Journal of Marketing Management 2: $155-169$.

13. Zukin S (2004) Consumers and Consumption. Annual Review of Sociology 30: 173-197.

14. Levitt T (1983) The globalization of markets. Harvard Business Review 61: 92-102.

15. Rosenbloom B, Andras TL (2008) Wholesalers as Global Marketers. Journal of Marketing Channels 15: 235-252.

16. Haxthausen $O$ (2008) Customer Focus Consumer goods companies need to think about retailers as their customers, not merely as a trade channel. Marketing Management 17: 39-42.
17. Calantone RJ, Cavusgil ST, Schmidt JB, Shin G (2004) Internationalization and the Dynamics of Product Adaptation-An Empirical Investigation. Journal of Product Innovation Management 21: 185-198.

18. Viswanathan NK (2007) The fundamentals of standardizing global marketing strategy. International Marketing Review 24: 46-63.

19. Onkvisit S, Shaw JJ (1999) Standardized International Advertising: Some Research Issues and Implications. Journal of Advertising Research pp: 19-26.

20. Karlícek M, Chytkova Z, Horejs N, Mohelska H, Fischer J (2013) The Role of Marketing in Multinational Subsidiaries: Standardization versus Localization. Ekonomie a Management pp: 138-148.

21. Melewar TC, Saunders J (1999) International corporate visual identity: Standardization or localization? Journal of International Business Studies 30: 583-598. 